\title{
Monitoring Land-Use Change in Nakuru (Kenya) Using Multi-Sensor Satellite Data
}

\author{
Kenneth Mubea ${ }^{1}$, Gunter Menz ${ }^{1,2}$ \\ ${ }^{1}$ Remote Sensing Research Group (RSRG), University of Bonn, Bonn, Germany \\ ${ }^{2}$ Center for Remote Sensing of Land surfaces (ZFL), University of Bonn, Bonn, Germany \\ Email: mubea@uni-bonn.de
}

Received October 9, 2012; revised November 15, 2012; accepted November 26, 2012

\begin{abstract}
Recently land-use change has been the main concern for worldwide environment change and is being used by city and regional planners to design sustainable cities. Nakuru in the central Rift Valley of Kenya has undergone rapid urban growth in last decade. This paper focused on urban growth using multi-sensor satellite imageries and explored the potential benefits of combining data from optical sensors (Landsat, Worldview-2) with Radar sensor data from Advanced Land Observing Satellite (ALOS) Phased Array type L-band Synthetic Aperture Radar (PALSAR) data for urban land-use mapping. Landsat has sufficient spectral bands allowing for better delineation of urban green and impervious surface, Worldview-2 has a higher spatial resolution and facilitates urban growth mapping while PALSAR has higher temporal resolution compared to other operational sensors and has the capability of penetrating clouds irrespective of weather conditions and time of day, a condition prevalent in Nakuru, because it lies in a tropical area. Several classical and modern classifiers namely maximum likelihood (ML) and support vector machine (SVM) were applied for image classification and their performance assessed. The land-use data of the years 1986, 2000 and 2010 were compiled and analyzed using post classification comparison (PCC). The value of combining multi-temporal Landsat imagery and PALSAR was explored and achieved in this research. Our research illustrated that SVM algorithm yielded better results compared to ML. The integration of Landsat and ALOS PALSAR gave good results compared to when ALOS PALSAR was classified alone. $19.70 \mathrm{~km}^{2}$ of land changed to urban land-use from non-urban land-use between the years 2000 to 2010 indicating rapid urban growth has taken place. Land-use information is useful for the comprehensive land-use planning and an integrated management of resources to ensure sustainability of land and to achieve social Equity, economic efficiency and environmental sustainability.
\end{abstract}

Keywords: Land-Use Monitoring; Nakuru; Urban Growth; Multi-Sensors Satellite Data; Maximum Likelihood; Support Vector Machine; Post Classification Comparison; Sustainability

\section{Introduction}

Quantitative urban studies are becoming increasingly important for planners knowing that in the year 2015 more than half the global population will be residing in cities [1]. Suitable urban planning ought to be a top priority for future development but unfortunately sound planning has not taken place especially in many African cities as heavy rural-urban migration continues to cause cities to expand at uncontrollable rates [2]. As a consequence, the urban population in Africa is increasing at a much faster rate than in the rest of the world, contributing to the augmentation of the existing problems such as unsuitable land-use [3]. The concentration of population in cities comprises as much as $60 \%$ of the total population in most countries. In these immense urban settlements the environmental and social consequences are sometimes disastrous [4].
Large cities in Africa such as Nakuru have experienced a fast growth rate of $13.3 \%$ between 1990 and 2006 [5]. The magnification has been attributed to a number of factors, mainly the aperture of the new Naivasha-Nakuru road, which links the megacity of Nairobi. Post-election violence is verbally expressed to be one of the contributing factors, since many displaced people from neighboring towns migrated to Nakuru as a safe shelter.

The main consequences in these African cities include; urban sprawl, unsuitable land-use, inadequate transportation systems, air and water pollution, depletion of natural resources, collapse of public services, proliferation of epidemics, and other negative environmental and social effects. The changing of surrounding area due to uncontrolled city development and city residents ever increaseing demand for energy, food, goods and other options is behind the deterioration of local and localized environ- 
ment which is harmful the basic environment solutions and biodiversity. Solutions of problems linked to unsustainable urban development in African cities are manifold and complex and requires an integrated spatially explicit approach. Such an integrated urban planning approach needs to recognize and anticipate urban dynamics and their consequences [6].

Remote sensing techniques have been valuable in mapping urban land-use pattern as well as data sources which aid in the analysis and modeling of urban growth and land-use change [7]. Remote Sensing offers spatially coherent data sets that cover large areas with both high spatial detail and high temporal frequency. These data characteristics are necessary for land-use monitoring, which is an essential element of socio-ecological studies. As urbanization occurs, changes in land-use accelerate and land making up the natural resource base such as forests and agricultural land, leading to modification and conversion of existing land-uses [8]. This is referred to as land take [9].

In order to assess the land-use in Nakuru town, it is best to evaluate spatial dimension of the imageries. The spatial dimension of remote sensing images as assessed by image texture contains information on local spatial structure and variability of land-cover categories, and can raise land-use classification accuracies in heterogeneous urban landscapes [10]. Texture information has improved classification accuracy for optical sensors such as the Satellite Pour l'Observation de la Terre (SPOT) High Resolution Visible (HRV) sensor, Landsat TM, Multispectral Electro optical Imaging Scanner (MEIS-II), and airborne multispectral sensors. The optimal window size for texture measurements is highly dependent on the image pixel size and the land cover characteristics [11]. Normally, window size should be large enough to include the entire texture pattern, and at the same time small enough to include only one land-cover type $[12,13]$.

Very high resolution SAR sensors are playing an increasingly important role in urban remote sensing due to their ability to operate day and night through cloud cover, recent improvement in data availability and spatial resolution [14]. Many studies have focused on the frequency and polarimetry of SAR data in land cover classification [15], whereas SAR image texture is found helpful in improving map accuracy, particularly for urban and forest categories [16].

Multi-temporal SAR images have proven to be useful in urban, forest, and agriculture land-cover classification [17]. Recent studies report that the fusion of optical and SAR data is useful due to their capability to distinct different features. Optical images contain information on surface reflectance and emissivity characteristics, while SAR images capture the structure and dielectric properties of the Earth surface materials [18]. Land-cover types that are impossible to separate in optical images might be distinguishable with SAR images and vice versa because of the complementary information contained in the two spectral domains [19].

Many approaches employing both optical and SAR images have been explored for land-cover classification [20,21]. The results from integrating optical and SAR sensors are often significantly higher than those obtained from using an individual sensor, particularly for certain land-use types, such as urban, agriculture and wetlands.

The study of land-use and land-cover changes is essential not only for land-use management but also in detecting environmental change and in formulating sustainable development strategies [22]. Accurate information on land-use changes is needed for documenting urban growth, making policy decisions and improving land-use planning. Information concerning land-use changes is also required for predictive modeling [23].

The aim of this research was to perform different land-use classification using multi-sensor data and to monitor land-use change. To achieve this optical and SAR datasets were obtained. Optical datasets included: Landsat of 1986, 2000 and 2010; Worldview-2 of 2010; and ALOS PALSAR imagery of the year 2010. Image classification was performed on resampled datasets at 12.5 meters and 28.5 meters. Several image classification algorithms were explored and their performance evaluated using accuracies measured such as overall accuracies and kappa coefficient values. Support vector machine (SVM) performed better compared to maximum likelihood classifier (ML). Thus combining images from optical and SAR yielded better results in image classification. Landuse change monitoring was achieved by comparing the change between two corresponding years and the result given as a percentage.

\section{The Study Area}

Nakuru municipality lies in Central Rift Valley in Kenya between latitudes $0^{\circ} 15^{\prime} \mathrm{S}$ and $0^{\circ} 31$ 'S, and longitude $36^{\circ} 00^{\prime} \mathrm{E}$ and $36^{\circ} 12^{\prime} \mathrm{E}$, with an average altitude of 1859 meters above sea level, covering an area of $290 \mathrm{~km}^{2}$ (Figure 1). Within Nakuru municipality is Nakuru town, and Lake Nakuru National Park. The Lake Nakuru National Park is a tourist attraction of great economic value for the country with Lake Nakuru being one of the largest bird sanctuaries in the world with the flamingo and pelican bird species. The town of Nakuru is located 160 km North West of Nairobi along the twin east-west railroad transport route from Mombasa to Kampala and is the fourth largest city in Kenya following Nairobi, Mombasa and Kisumu. The administratively defined city has land-uses divided into urban use, agriculture, range land and remnants of evergreen tropical forests. Such 


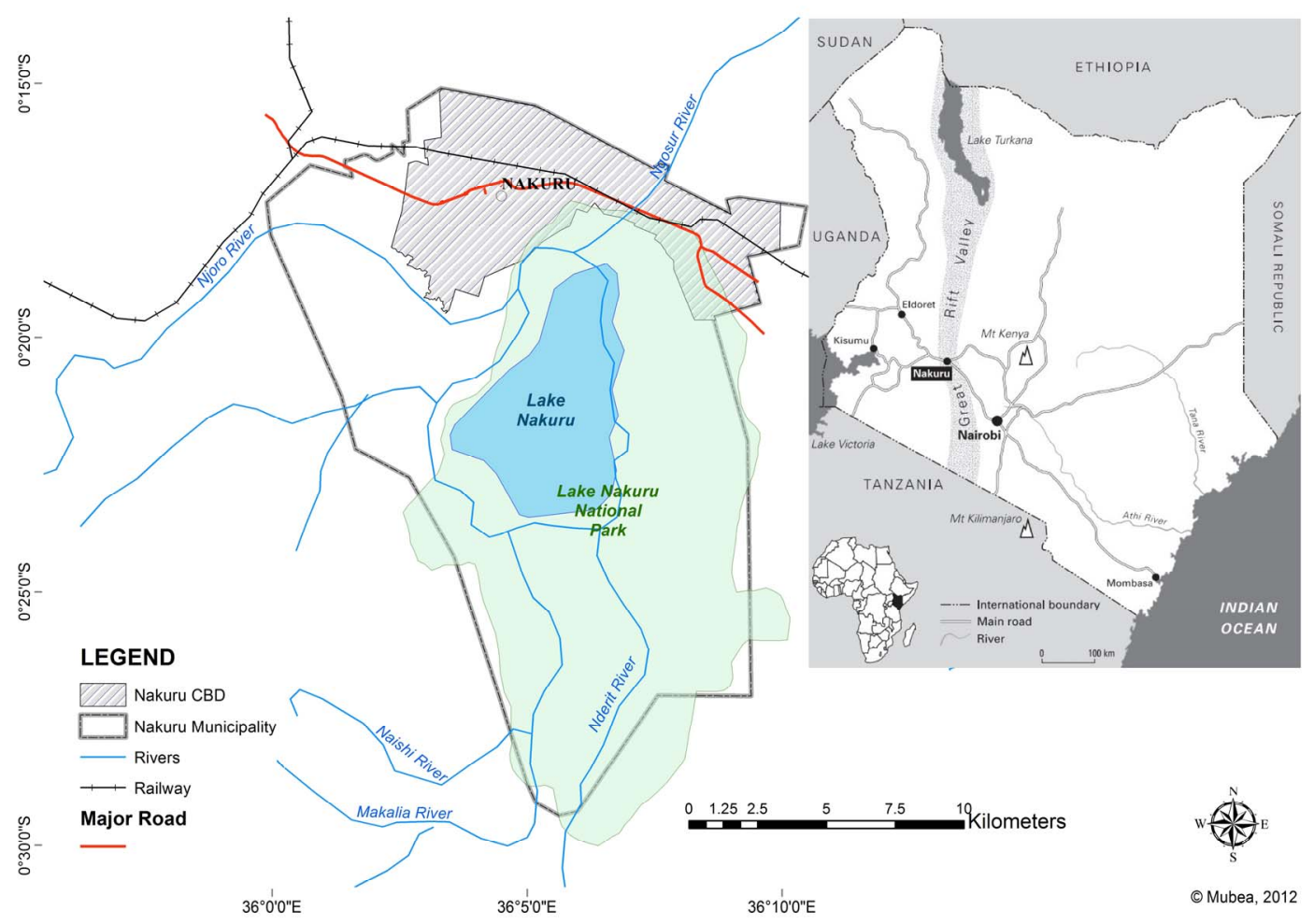

Figure 1. Location of Nakuru in the central rift valley of kenya (source: World Resource Institute).

land-uses are similar to other cities in Kenya and sub Saharan Africa [2].

\section{Urban Growth Rates}

The urban pattern of Nakuru town and its environs are characterized by intense urban pressures, first along the main highways and through the development of sub urban areas. Nakuru population has been growing at the rate of 5.6\% per annum. From a population of 38,181 in 1962, the population reached 47,151 in 1969 [24], 92,851 in 1979 [25], 163,927 in 1989 [26], and 289,385 in 1999 [27]. By the year 2015, the population is projected to rise to 760,000 , which is approximately $50 \%$ above the present levels [28].

As a consequence of this population development, urban sprawl has led a negative impact on infrastructure and the sustainability of cities [29].This has led to; spontaneous slum developments, large increase in the number of street children, unemployment and high rates of crime, strain on existing urban infrastructure and services, and many urban areas are faced with severe environmental problems for example air pollution.

With respect to institutional arrangements, the local governments, entrusted with the provision of urban basic infrastructure, have been unable to perform as a result of administrative problems and lack of capability [29].

In order to address urban growth in Nakuru, this re- search utilized a multi-sensor approach. Landsat, Worldview-2 and ALOS-PALSAR data were used to better delineate urban land-use and its change within Nakuru municipality.

\section{Utility of Multi-Sensor Satellite Data}

Urban landscapes remain one of the most challenging environments to be analyzed from remotely sensed data. They are complex, featuring spatial and spectral heterogeneity and are composed of multi-fold artificial and natural surface types [30]. In a comparative analysis of urban reflectance, [31] concluded that sensors with similar spectral and radiometric properties to Landsat Thematic Mapper (TM) principally comprise a three- dimensional spectral feature space. In such a feature space, linear combinations of spectral end members (high albedo, vegetation and low albedo) cover approximately $98 \%$ of the variance contained in an urban scene [32].

Challenges of urban mapping can be solved using more temporal information and data from different sensors. Integrating multi-temporal information helps distinguish urban from non-urban surfaces as urban spectral responses are largely persistent over time compared to non-urban surface phenology [32].

Combining multi-spectral imagery with data from the microwave spectral domain has also proven to be a powerful strategy, especially for monitoring urban areas and 
for overcoming spectral ambiguities [33,34]. The combined use of synthetic aperture radar (SAR) and multispectral optical imagery has been successfully used to delineate built-up areas [35].

Urban mapping requires the selection of an appropriate scale of observation. This involves a certain trade-off between the richness of detail of very high resolution (VHR) remote sensing imagery and the generalizing nature of moderate to high resolution sensors such as the 30 $\mathrm{m}$ of Landsat data [32]. The long-term and future data record is an advantage of Landsat data [36,37] compared to very high resolution sensors. Optical and SAR systems operate in different wavelengths, ranging from visible to microwave.

Landsat sensors include MSS (Multi-Spectral Scanner), TM (Thematic Mapper) and ETM+ (Enhanced Thematic Mapper Plus). Figure 2 illustrates a false color composite Landsat RGB (red, green and blue bands) and panchromatic band of Nakuru municipality. World view-2 was launched on 8th October 2009. It is the first comercial eight multispectral bands high resolution satellite (sensor). Figure 3 illustrates Worldview-2 True color bands of the central business district (CBD) of Nakuru.

Radar wavelength has an ultimate influence on the interaction between the electromagnetic wave and the natural medium [38]. As wavelength increases, surface roughness criteria will also change. In general, more surface features will appear smoother at longer wavelengths than at shorter wavelengths.

The capability to penetrate through precipitation clouds or into a surface layer is increased with longer wavelengths. Typically the penetration is half the wavelength and as wavelength increases and frequency decreases, respectively, the penetration becomes higher [39].

Radar is able to receive and process all four combinations of polarizations: $\mathrm{HH}, \mathrm{HV}, \mathrm{VH}$, and VV. $\mathrm{HH}$ stands for horizontal transmit and horizontal receive, VV stands for vertical transmit and vertical receive, $\mathrm{HV}$ stands for horizontal transmit and vertical receive, and $\mathrm{VH}$ stands for vertical transmit and horizontal receive. $\mathrm{HH}$ and VV are referred to as like-polarized because the transmit and receive polarizations are the same, while $\mathrm{HV}$ and $\mathrm{VH}$ are referred to as cross-polarized because the transmit and receive polarizations are orthogonal to one another. The channels have varying sensitivities to differentiate surface characteristics and properties. For instance, the dynamic range of the like-polarized module is larger than that of the cross-polarized module for urban areas; this is in contrast to the measurement for forested areas, where the dynamic range of the cross-polarized component is larger than that of the like-polarized component [40].

Multiple polarizations help to distinguish the physical structure of the scattering surfaces e.g. $\mathrm{HH}$ vs. VV is

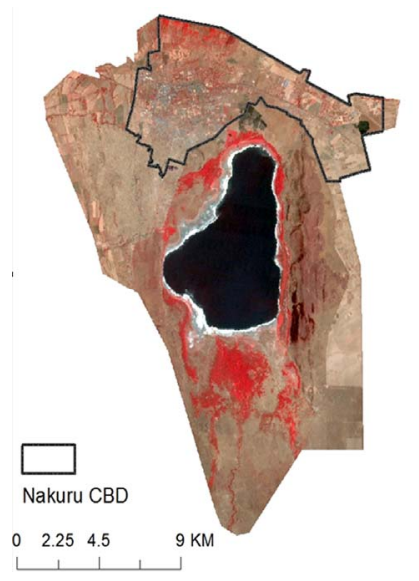

(a)

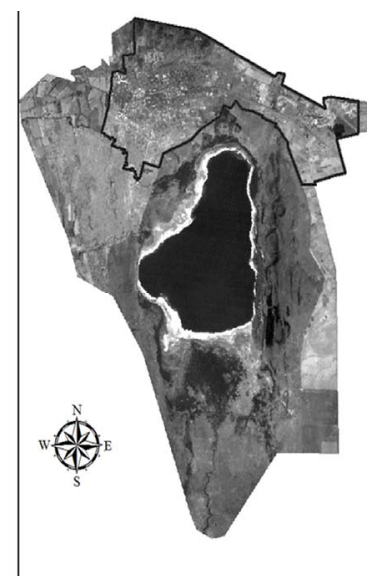

(b)
Figure 2. (a) False color composite Landsat tm (path 169, row 60) RGB of 1986 for Nakuru municipality (b) panchromatic band of 1986 for Nakuru municipality.

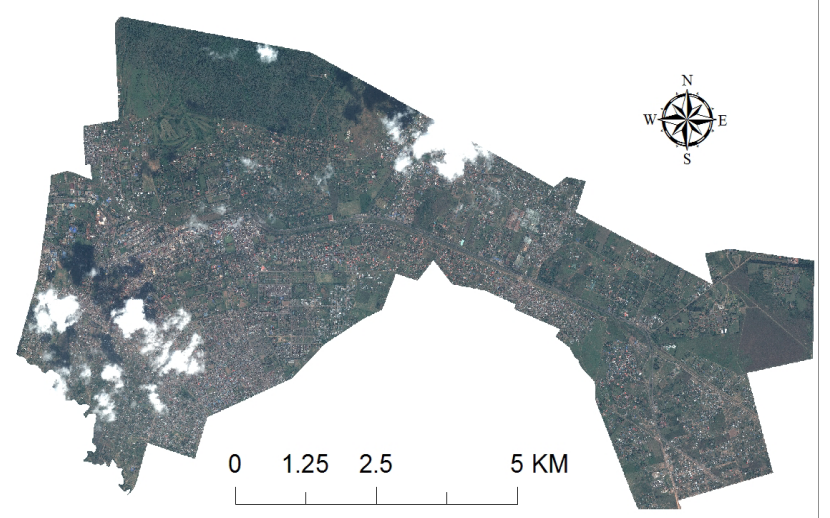

Figure 3. Worldview-2 true color image of year 2010 for Nakuru CBD (extend of CBD see Figure 2).

used in the alignment with respect to the radar, $\mathrm{HV}$ is used in the randomness of scattering for vegetation cover, $\mathrm{HH}$ and VV phase angle is used for the corner structures and urban land-use mapping.

Past studies showed that radar imagery collected using different polarization may provide different and complementary information about the targets on the surface and thus improve the interpretation of different urban features [40]. The use of polarimetric datasets for urban analysis has been accelerated in recent years with more and more fully-polarimetric SAR systems being in operation for example Terra SAR-X. Several studies demonstrated that polarimetric datasets have great potential for urban applications [38,41].

\section{Analysis}

\subsection{Data}

The approach adopted for the analysis of land-use invol- 
ved: Landsat images for 1986, 2000 and 2010, Worldview-2; and Advanced Land Observing Satellite (ALOS) Phased Array type L-band Synthetic Aperture Radar (PALSAR) image for 2010 were selected for the study area. The ALOS PALSAR was at level 1.5 and polarimetric mode, multi-polarized images, HH Horizontal-Horizontal + HV Horizontal-Vertical + VerticalHorizontal + VV Vertical-Vertical. Nakuru municipality is entirely contained within Landsat TM path 169, rows 60. The Landsat data sets include TM, and ETM + images. Digital elevation model (DEM) at spatial resolution of 90 meters was obtained from the United States Geological Survey (USGS) and used to pre-process the SAR data. Reference data included a topographic map (scale 1:50,000) and ground truth information about land-use from 50 GPS points which were used for classifier training and accuracy assessment. Stratified random sampling was adopted for selecting samples.

\subsection{Land-Use Classification}

Two approaches were implemented for the land-use classification of Nakuru; Nakuru municipality with six landuse classes (namely urban, water, forest, agriculture, barren land and rangeland) and Nakuru Central Business District (CBD) with three land-use classes (namely urban, forest and agriculture). The three classes were selected for Nakuru CBD since it is the center of major activities and infrastructure. Several factors were considered during the design of categorization scheme such as the major land-use categories within the research area, disparities in spatial rules of the sensors, and the need to always discriminate land-use classes irrespective of seasonal disparities [42].

Image pre-processing steps for the optical datasets were radiometric and geometric correction as illustrated in Figure 4. GPS points were used for image to map registration. UTM 37 South was selected as reference system for the research area. The processing of the SAR data was done using European Space Agency (ESA)

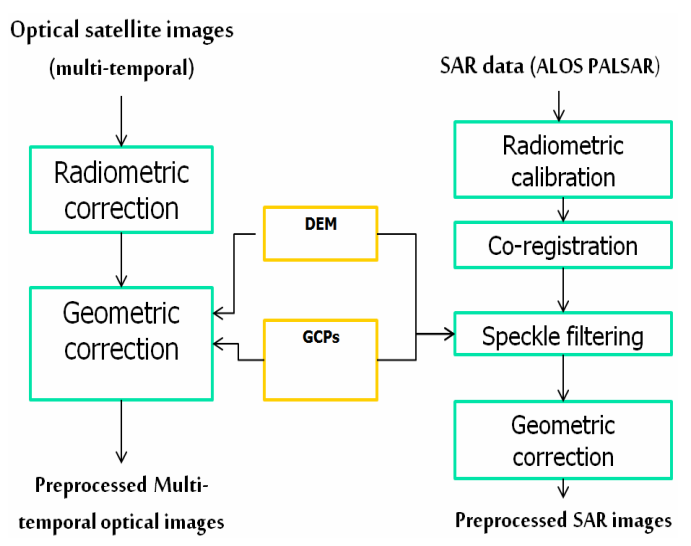

Figure 4. Image preprocessing workflow of the multi-sensor satellite data sets.
NEST SAR Remote Sensing software. Multi-look correction was applied. Radar speckle which appear as grainy "salt and pepper" texture in imagery, was reduced prior to interpretation and analysis using Gamma Map filter with $5 \times 5$ kernel. The DEM used was an SRTM (Shuttle Radar Topography Mission) and was used to remove relief displacement in SAR data

In order to find the optimal spatial resolution scenarios of upscaling and downscaling of the data sets were explored. Upscaling refers to the decrease in spatial resolution while downscaling is the increase in spatial resolution.

Scale has several definitions according to [43] namely: cartographic or map scale; observational or geographic scale that refers to the size or spatial extent of the study; measurement scale or resolution that refers to the minimum size that can be distinguished; and finally operational scale that refers to the scale at which certain processes operate in the environment.

In a nutshell, scale is the spatial and temporal dimension of the research while at the same time; scale also refers to the spatial extent and frequency that a certain phenomenon or process occurs [44]. Additionally, scale shows the level on which the object is understood. Hence scale can either be temporal or spatial scale, and of which both were investigated in this research. Combinations of the reflective spectral bands from images (i.e., stacked vector) were used for classification of the 1986, 2000 and 2010 images. The ratio of $\mathrm{HH} / \mathrm{HV}$ was used for the case of the ALOS PALSAR imagery which yields best results for urban areas $[18,45]$.

Image processing techniques were applied to the data sets both at spatial resolution of 12.5 meters and 28.5 meters using nearest neighbor interpolation. Therefore the Worldview-2 data was resampled from 0.5 meters (original) to 12.5 meters and 28.5 meters. Landsat was resampled from 28.5 meters (original) to 12.5 meters while ALOS PALSAR was resampled from 12.5 meters (original) to 28.5 meters. The objective was to assess how classification accuracy changes with spatial resolution. Image processing workflow is illustrated in Figure 5.

Training sites representing the land-use classes of interest were collected using the region growing tool in ENVI 4.8. Such sites were homogeneous and extensive to provide excellent statistics. ML was applied to the multi-sensor datasets, and performance assessed using the corresponding confusion matrices.

SVM classification in ENVI 4.8 was applied to all the data sets and its performance assessed using confusion matrices. The SVM classifier has four kernels namely linear, polynomial, Radial Basis Function (RBF) and sigmoid. Radial basis function kernel is the default and works well in most situations [46]. 
SVM is well recognized in the field of machine learning and pattern recognition [47] and has recently been introduced in context of remote sensing image analysis [48]. SVM has been applied successfully for classifying multispectral imagery for example in [49] and outperformed other methods in the very most recent cases. In some studies SVM has been seen to produce higher accuracies than other classifiers, as a maximum likelihood classifier, an ANN and a simple decision tree [48]. Different voting schemes for multi class SVMs have been explored [48].

Post-classification refinements were enforced to diminish categorization errors as a result of the similarities in spectral responses of certain training classes such as bare fields and urban areas and some crop fields and wetlands. Independent samples of about 100 pixels for each class were randomly selected from each classifica tion category to assess classification accuracies. Confusion matrices as cross-tabulations of the mapped classversus the reference class were used to assess classification accuracies [50]. Overall accuracy, user's and producer's accuracies, and the Kappa statistic were then derived from the error matrices. The Kappa statistic incorporates the off diagonal elements of the confusion matrices (i.e., classification errors) and represents agreement obtained after removing the proportion of agreement that could be expected to occur by chance. Following the classification of imagery from the individual years, a GIS based multi-date post classification coeparison (PCC) change detection strategy was employed to determine changes in land-use in Nakuru. Change detection analysis entailed finding the type, amount and location of land use changes that had taken place.

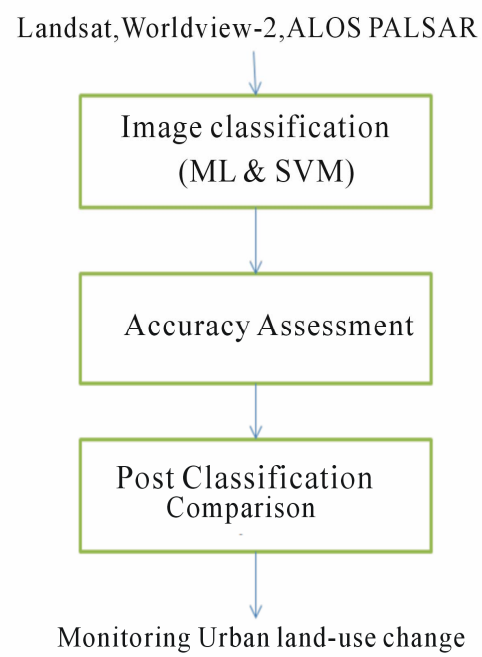

Figure 5. Image workflow for classification and change detection of multi-sensor data sets.

\section{Results and Discussion}

Image classification of Landsat for 1986, 2000 and 2010 with 28.5 meters (original) spatial resolution was successfully performed and the results tabulated in Table $\mathbf{1 .}$ SVM produced better results compared to ML for example SVM in 2010 yielded an overall accuracy of $86.96 \%$ compared to ML of the same year with $83.80 \%$. Land-use maps for Nakuru municipality for the three years are illustrated on Figure 6.

Furthermore the Radial Basis Function (RBF) kernel of support vector machine at various percentages was explored. RBF performed best at 0.33 compared to 0.5 and 0.7 . The RBF value of 0.33 is the default value in ENVI software. For example the overall accuracy value of $93.42 \%$ was obtained for the year 1986 at RBF value of 0.33 compared to $93.14 \%$ at 0.5 and $93.14 \%$ at 0.7 . Similarly an overall accuracy value of $83.77 \%$ was obtained for the year 2000 at RBF value of 0.33 compared to $82.75 \%$ at 0.5 and $82.75 \%$ at 0.7 .

Land-use summary for Nakuru municipality (using Landsat at spatial resolution of 28.5 meters) was performed in ENVI and results tabulated in Table 2. SVM gave better results compared to ML. For example, looking at the urban class, using SVM growth was from 4.78 $\mathrm{km}^{2}$ in 1986, $12.73 \mathrm{~km}^{2}$ in 2000 and $27.84 \mathrm{~km}^{2}$ in 2010 compared to ML.

Next we analyzed the upscaling of World view-2 and ALOS for Nakuru CBD which yielded low classification accuracy as shown in Table 3. World view-2 was up scaled from 0.5 to 28.5 meters and ALOS PALSAR from 12.5 to 28.5 meters.

Land-use summary for Nakuru CBD, using all data sets at spatial resolution of 28.5 meters, was performed in ENVI and results tabulated in Table 4. From Table 4 the respective SVM values of Landsat 2010, Worldview-2 and ALOS PALSAR for the three land-uses were different because of the different sizes of the training polygons and heterogeneity of the individual land-use classes.

Land-use summary for Nakuru CBD, using all data sets at spatial resolution of 12.5 meters, was performed in ENVI and results tabulated in Table 5. Relatively good

Table 1. Confusion matrix for land-cover classification for nakuru municipality (landsat data from 1986, 2000 \& 2010).

\begin{tabular}{|c|c|c|c|c|}
\hline Method & & Land & & \\
\hline \multirow{3}{*}{ SVM } & & 1986 & 2000 & 2010 \\
\hline & $\begin{array}{c}\text { Overall } \\
\text { Accuracy }\end{array}$ & $93.42 \%$ & $83.77 \%$ & $86.96 \%$ \\
\hline & $\begin{array}{c}\text { Kappa } \\
\text { Coefficient }\end{array}$ & 0.9087 & 0.7988 & 0.8393 \\
\hline \multirow{2}{*}{ ML } & $\begin{array}{c}\text { Overall } \\
\text { Accuracy }\end{array}$ & $89.00 \%$ & $82.50 \%$ & $83.80 \%$ \\
\hline & $\begin{array}{c}\text { Kappa } \\
\text { Coefficient }\end{array}$ & 0.8527 & 0.7862 & 0.8025 \\
\hline
\end{tabular}




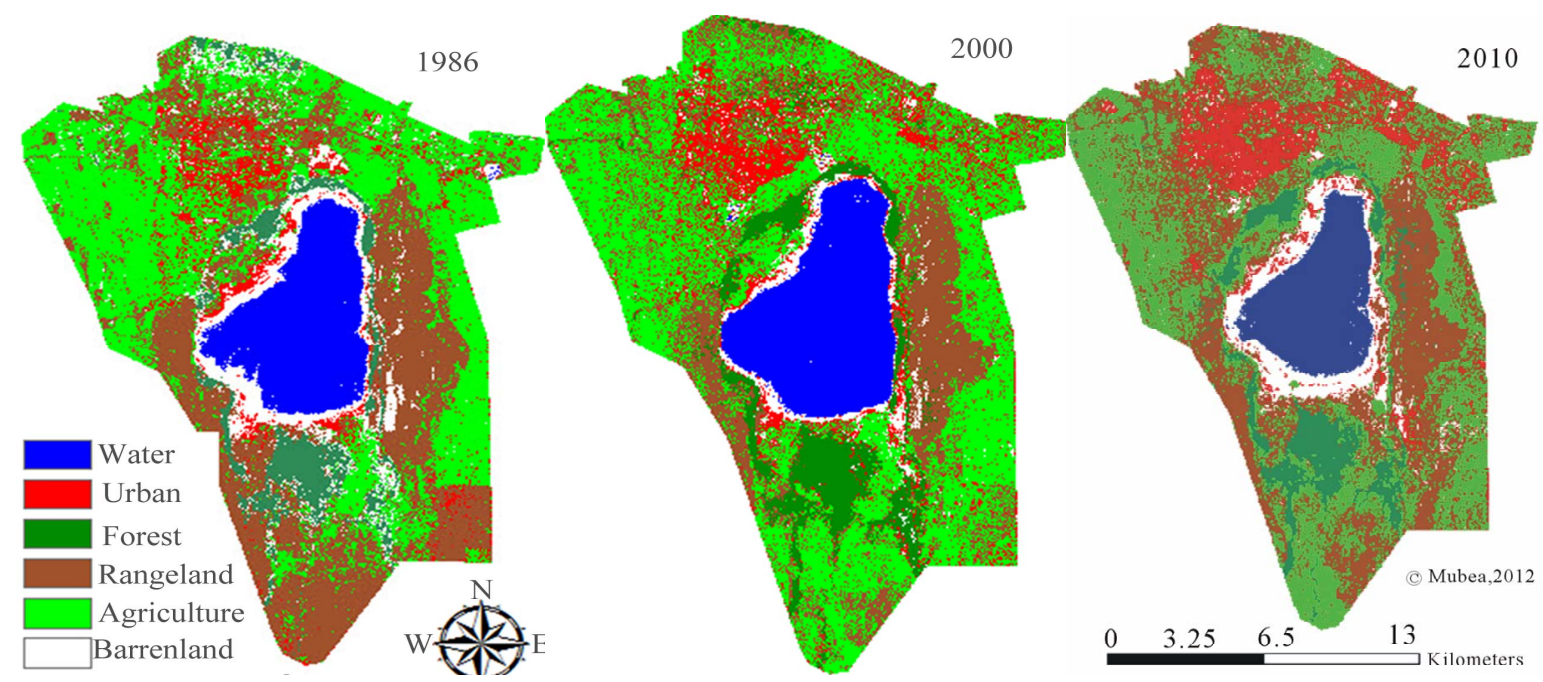

Figure 6. Land-use map for Nakuru municipality from Landsat for 1986, 2000 and 2010.

values of urban class were achieved using SVM ALOS data as compared to Landsat data and World view-2 at 12.5 meters spatial resolution. Land-use maps for Nakuru CBD are illustrated in Figures 7-10.

From the Table 6, downscaling of Landsat data sets did not affect classification accuracy. Landsat was downscaled from 28.5 meters to 12.5 meters. For example, the kappa coefficient value of $96.18 \%$ in Table 3 for Landsat 1986 classification is close to that one of $96.23 \%$ in Table 6 of the same data set classification using SVM.

The ratio of $\mathrm{HH} / \mathrm{HV}$ ALOS PALSAR was combined with (bands 2, 3, 4) Landsat 2010 as a layer stack and SVM carried out. The combined ALOS PALSAR (2010) and Landsat (2010) gave better results in terms of classification accuracies. For example an overall accuracy value of $93.64 \%$ and kappa statistic 0.8795 was obtained using the combined Landsat and ALOS PALSAR compared to that of ALOS PALSAR alone 84.09\% and 0.6878 respectively as illustrated on Table 6 using SVM.

Based on the results from the different image classification, land-use change was calculated using post classification technique and results tabled in Table 7 and maps illustrated on Figures 11 and 12. From Table 7, 6.25 $\mathrm{km}^{2}$ of land changed to urban land-use from non-urban between the years 1986 to 2000 compared to the value of $19.70 \mathrm{~km}^{2}$ between the years 2000 to 2010 . Non-urban land-use included forest and agriculture land-uses. Thus rapid urban growth has taken place between the years 2000 to 2010 due to urbanization. This has been witnessed by the high population growth $[27,28]$, and rapid infrastructure developments such as more houses to cater for the growing demand for housing

\section{Conclusion}

Monitoring urban land-use and spatial-temporal changes is essential for guiding decision making in resource management. We analyzed land-use changes between 1986 and 2010 using multi-sensor satellite datasets. The performances of various classifiers were assessed. SVM algorithm gave better results compared to ML classifier. Image upscaling and downscaling were explored in this

Table 2. Land-use estimates for Nakuru municipality using Landsat (28.5 spatial resolution).

\begin{tabular}{ccccccc}
\hline & \multicolumn{2}{c}{1986} & \multicolumn{2}{c}{2000} & \multicolumn{2}{c}{2010} \\
\hline $\begin{array}{c}\text { Land cover classes } \\
\left(\mathrm{km}^{2}\right)\end{array}$ & MLC & SVM & MLC & SVM & MLC & SVM \\
\hline Water & 33.29 & 36.95 & 38.77 & 40.09 & 27.25 & 30.78 \\
Urban & 16.65 & 4.78 & 26.4 & 12.73 & 26.83 & 27.84 \\
Forest & 16.95 & 20.55 & 25.77 & 27.1 & 21.91 & 26.93 \\
Barren land & 24.69 & 13.46 & 9.5 & 5.98 & 18.82 & 19.84 \\
Rangeland & 93.63 & 150.07 & 70.44 & 134 & 111.15 & 122.57 \\
Agriculture & 104.78 & 64.2 & 119.12 & 70.1 & 84.03 & 62.03 \\
Total & 290 & 290 & 290 & 290 & 290 & 290 \\
\hline
\end{tabular}

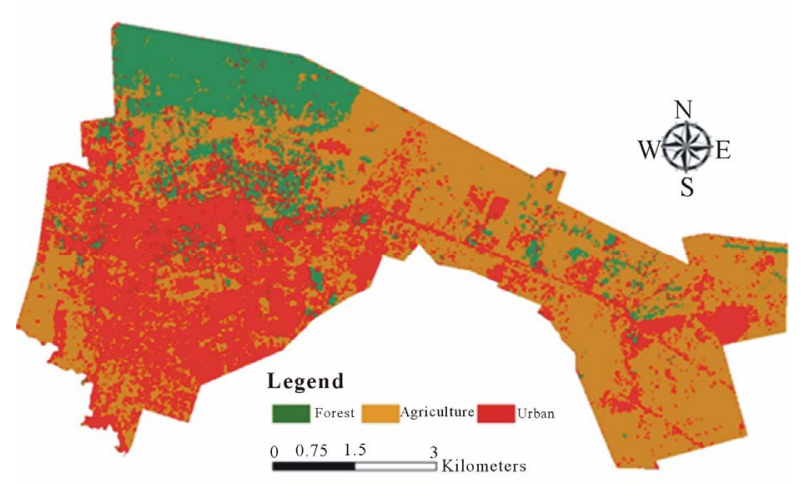

Figure 7. Land-use map for Nakuru CBD using Landsat TM 1986. 


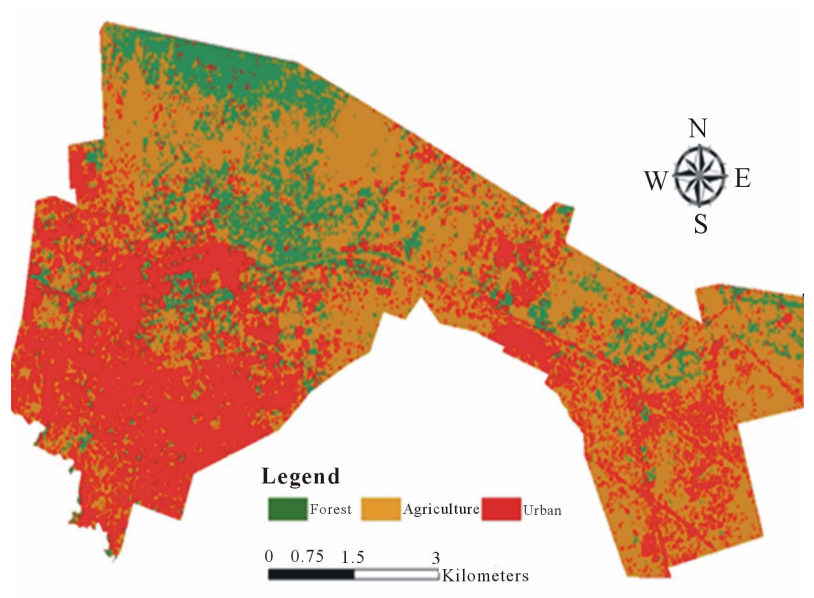

Figure 8. Land-use map for Nakuru CBD using Landsat ETM 2000.

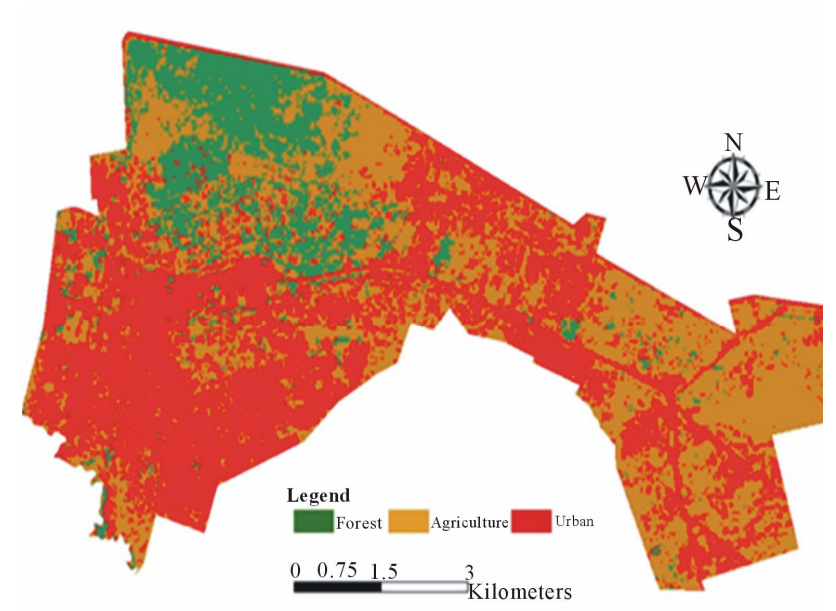

Figure 9. Land-use map for Nakuru CBD using Landsat ETM+ 2000.

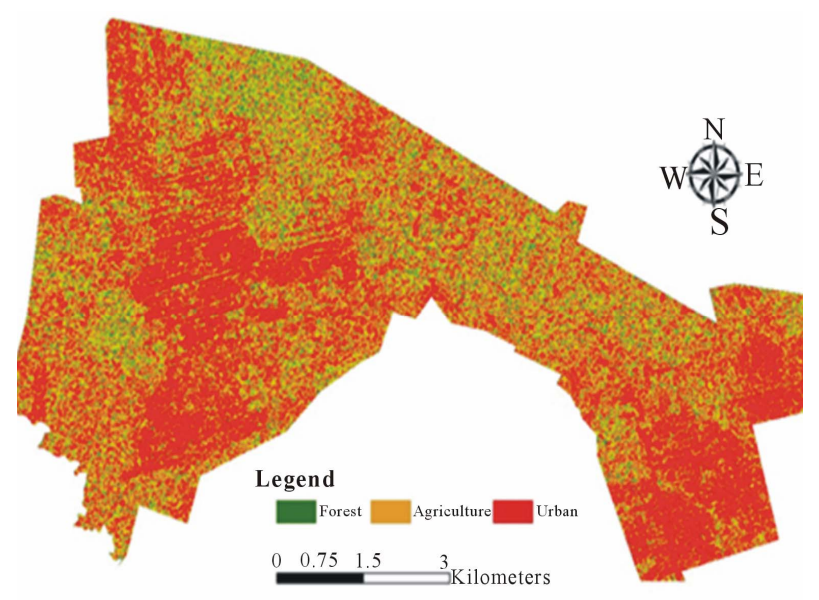

Figure 10. Land-use map for Nakuru CBD using ALOS PALSAR 2010.
Table 3. Comparison of classification accuracies for the three multi-sensor data sets at $\mathbf{2 8 . 5}$ spatial resolution for Nakuru CBD.

\begin{tabular}{|c|c|c|c|c|c|c|}
\hline \multirow[t]{2}{*}{ Method } & & \multicolumn{3}{|c|}{ Landsat } & \multirow{2}{*}{$\begin{array}{c}\text { Worldview } \\
-2 \\
2010\end{array}$} & \multirow{2}{*}{$\begin{array}{c}\begin{array}{c}\text { Alos } \\
\text { palsar }\end{array} \\
2010\end{array}$} \\
\hline & & 1986 & 2000 & 2010 & & \\
\hline \multirow{2}{*}{ SVM } & $\begin{array}{c}\text { Overall } \\
\text { Accuracy }\end{array}$ & $96.18 \%$ & $93.22 \%$ & $99.51 \%$ & $76.76 \%$ & $59.37 \%$ \\
\hline & $\begin{array}{c}\text { Kappa } \\
\text { Coefficient }\end{array}$ & 0.9343 & 0.7321 & 0.9914 & 0.6358 & 0.3555 \\
\hline \multirow{2}{*}{ ML } & $\begin{array}{l}\text { Overall } \\
\text { Accuracy }\end{array}$ & $95.24 \%$ & $93.22 \%$ & $99.60 \%$ & $76.76 \%$ & $18.62 \%$ \\
\hline & $\begin{array}{l}\text { Kappa } \\
\text { Coefficient }\end{array}$ & 0.9196 & 0.7321 & 0.9929 & 0.6358 & 0.0000 \\
\hline
\end{tabular}

Table 4. Land-use estimates for Nakuru CBD (28.5 spatial resolution).

\begin{tabular}{cccccc}
\hline \multirow{2}{*}{$\begin{array}{c}\text { Land-cover } \\
\text { classes }\left(\mathrm{km}^{2}\right)\end{array}$} & Landsat & & $\begin{array}{c}\text { Worldview } \\
-2\end{array}$ & $\begin{array}{c}\text { ALOS } \\
\text { PALSAR }\end{array}$ \\
\cline { 2 - 6 } & 1986 & 2000 & 2010 & 2010 & 2010 \\
\hline & SVM & SVM & SVM & SVM & SVM \\
Forest & 11.28 & 6.45 & 12.15 & 16.1 & 11.26 \\
Urban & 34.35 & 30.96 & 30 & 22.25 & 17.38 \\
Agriculture & 12.37 & 20.59 & 15.85 & 19.64 & 29.36 \\
Total & 58 & 58 & 58 & 58 & 58 \\
\hline
\end{tabular}

Table 5. Land-use estimates for Nakuru CBD (12.5m spatial resolution).

\begin{tabular}{cccccc}
\hline \multirow{2}{*}{$\begin{array}{c}\text { Land-cover } \\
\text { classes }\left(\mathrm{km}^{2}\right)\end{array}$} & \multicolumn{2}{c}{ Landsat } & & $\begin{array}{c}\text { Worldview } \\
-2\end{array}$ & $\begin{array}{c}\text { ALOS } \\
\text { PALSAR }\end{array}$ \\
\cline { 2 - 6 } & 1986 & 2000 & 2010 & 2010 & 2010 \\
\hline & SVM & SVM & SVM & SVM & SVM \\
\hline Urban & 15.91 & 18.89 & 23.31 & 23.55 & 27.76 \\
Forest & 8.94 & 9.23 & 9.67 & 14.1 & 7.07 \\
Agriculture & 33.15 & 29.88 & 25.02 & 20.35 & 23.17 \\
Total & 58 & 58 & 58 & 58 & 58 \\
\hline
\end{tabular}

research. Downscaling of Landsat data sets did not affect classification accuracy as compared to upscaling of Worldview-2 and ALOS PALSAR datasets. The integration of Landsat and ALOS PALSAR yielded good results compared to when ALOS PALSAR was classified alone. Post classification comparison was performed to determine the land-use changes and conversion.

The information obtained however, is very useful for planning purposes and for the appropriate allocation of resources and demonstrate the potential of combining multi-sensor Landsat data, Worldview-2, and PALSAR data to provide precise means to analyze and map changes in urban land-use. Moreover, such information can be used as inputs to decision support systems, policy decisions and land management. 


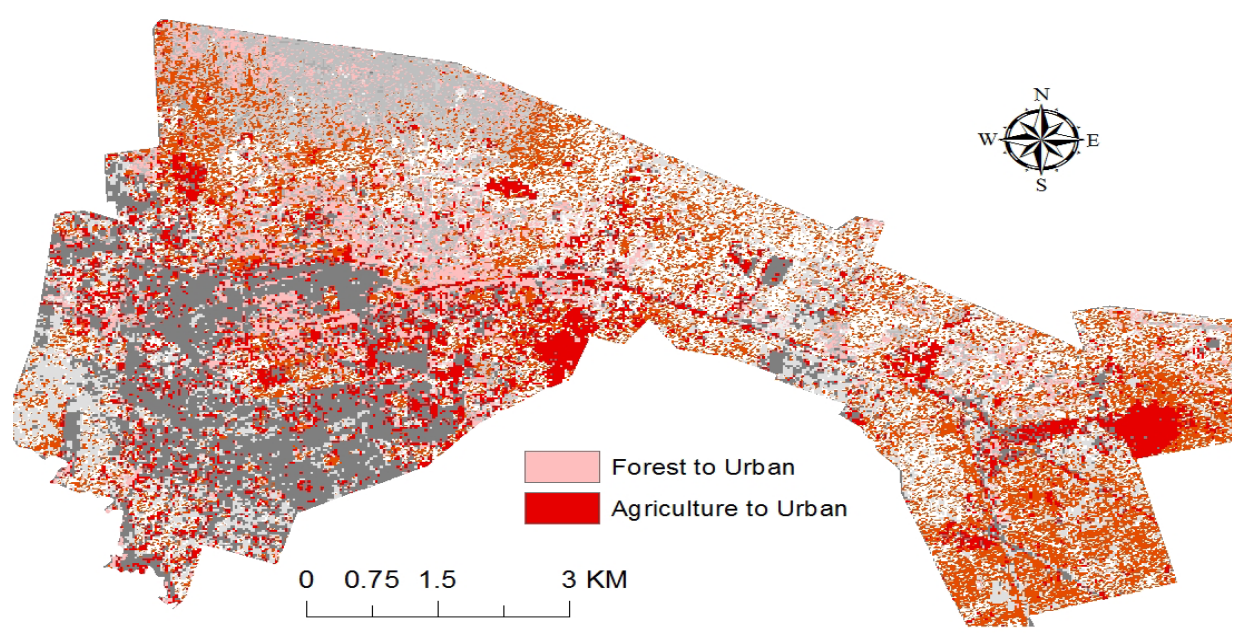

Figure 11. Land-use change in Nakuru CBD using Landsat TM (1986) and Landsat ETM (2000).

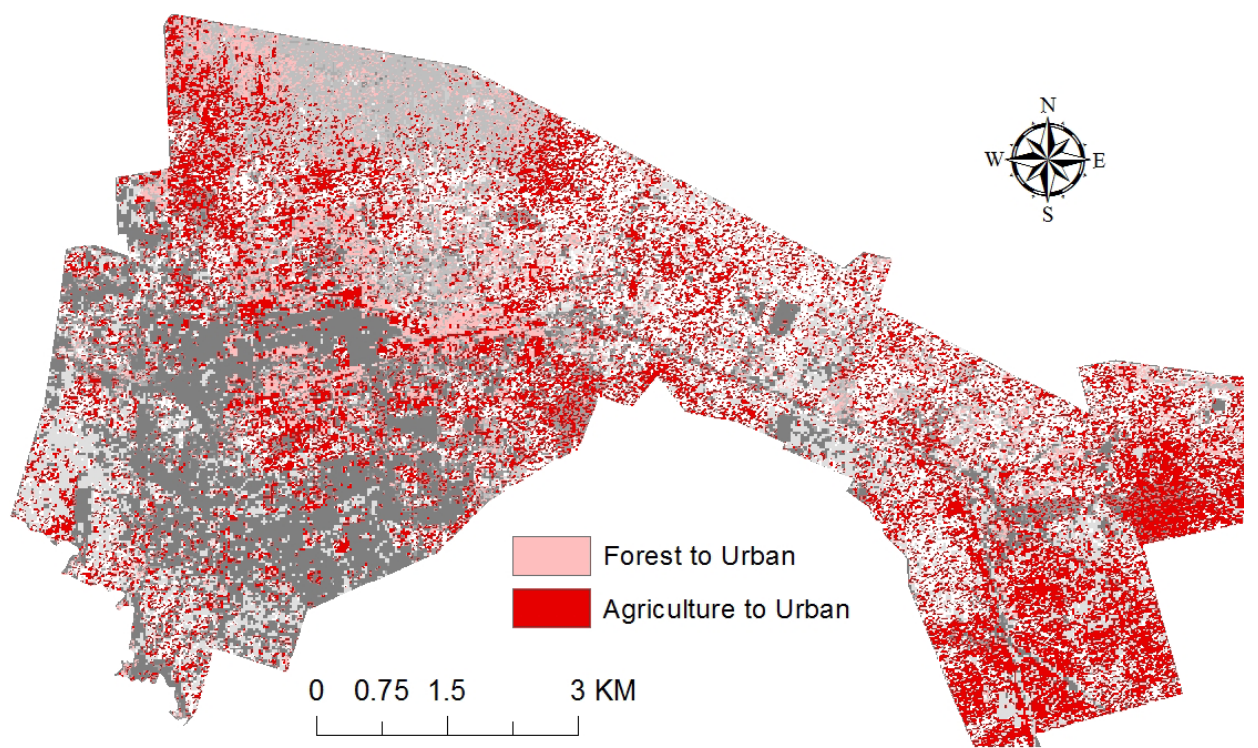

Figure 12. Land-use change in Nakuru CBD using Landsat ETM (2000) and ALOS PALSAR (2010).

Table 6. Confusion matrix for land-use classification for Nakuru CBD (12.5 spatial resolution).

\begin{tabular}{|c|c|c|c|c|c|c|}
\hline & & & Landsat & & $\begin{array}{c}\text { Worldview } \\
-2\end{array}$ & $\begin{array}{c}\text { ALOS } \\
\text { PALSAR }\end{array}$ \\
\hline & & 1986 & 2000 & 2010 & 2010 & 2010 \\
\hline \multirow{2}{*}{ SVM } & $\begin{array}{l}\text { Overall } \\
\text { Accuracy }\end{array}$ & $96.23 \%$ & $96.91 \%$ & $99.05 \%$ & $77.47 \%$ & $84.09 \%$ \\
\hline & $\begin{array}{c}\text { Kappa } \\
\text { Coefficient }\end{array}$ & 0.943 & 0.9507 & 0.9836 & 0.6343 & 0.6878 \\
\hline \multirow{2}{*}{ ML } & $\begin{array}{l}\text { Overall } \\
\text { Accuracy }\end{array}$ & $96.66 \%$ & $97.09 \%$ & $98.68 \%$ & $77.47 \%$ & $21.00 \%$ \\
\hline & $\begin{array}{c}\text { Kappa } \\
\text { Coefficient }\end{array}$ & 0.9495 & 0.9485 & 0.9774 & 0.6343 & 0.0000 \\
\hline
\end{tabular}

Table 7. Land-use change estimates based on post classification comparison.

\begin{tabular}{ccc}
\hline & 1986 to 2000 & 2000 to 2010 \\
\hline Land-use change & Change $\left(\mathrm{Km}^{2}\right)$ & Change $\left(\mathrm{Km}^{2}\right)$ \\
\hline No change & 36.69 & 23.69 \\
From non-urban to urban & 6.25 & 19.70 \\
from urban to non-urban & 8.93 & 7.75 \\
\hline
\end{tabular}

\section{Acknowledgements}

The authors would like to acknowledge European Space 
Agency (ESA) for providing ALOS PALSAR data and the Regional Centre for Mapping of Resources for Development (RCMRD, in Nairobi, Kenya) for providing Landsat 2010 and Worldview-2 which was significant for this research. Additionally the authors are grateful to German Academic Exchange Service (DAAD) and National Council for Science and Technology (NCST in Nairobi, Kenya) for providing the stipend to facilitate this research. Furthermore the authors acknowledge the contribution of the anonymous reviewers for their useful comments.

\section{REFERENCES}

[1] UNECE, "Trends in Europe and North America," The Statistical Yearbook of the Economic Commission for Europe, 2003.

[2] C. N. Mundia and M. Aniya, "Modeling Urban Growth of Nairobi City Using Cellular Automata and Geographical Information Systems," Geographical Review of Japan, Vol. 80, No. 12, 2007, pp. 777-788. doi:10.4157/grj.80.777

[3] C. Lavalle, L. Demichili, M. Turchini, P. Casals Carrsco and M. Niederhuber, "Monitoring Mega-Cities: The MURBANDY/MOLAND Approach," Development in Practice, Vol. 11, No. 2-3, 2001, pp. 350-357. doi:10.1080/09614520120056478

[4] J. I. Barredo and L. Demicheli, "Urban Development in Mega Cities: Modeling and Predicting Future Urban Growth,” Cities, Vol. 20, No. 5, 2003, pp. 297-310. doi:10.1016/S0264-2751(03)00047-7

[5] UN-HABITAT, “State of the World Cities 2010/2011,” 2010. http://www.unhabitat.org/documents/SOWC10/R4.pdf

[6] C. N. Mundia, M. Aniya and Y. Murayama, "Modeling Spatial Processes of Urban Growth in an African City. A Case Study of Nairobi," Nova Science Publishers, New York, 2010.

[7] K. C. Clarke, B. O. Parks and M. P. Crane, "Geographic Information Systems and Environmental Modeling," Prentice Hall, Upper Saddle River, 2002.

[8] C. N. Mundia and M. Aniya, "Dynamics of Land-Use/ Cover Changes and Degradation of Nairobi City, Kenya," Land Degradation and Development, Vol. 17, No. 1, 2006, pp. 97-108. doi:10.1002/ldr.702

[9] G. Tóth, "Impact of Land-Take on the Land Resource Base for Crop Production in the European Union," Science of the Total Environment, Vol. 435-436, 2012, pp. 202-214. doi:10.1016/j.scitotenv.2012.06.103

[10] B. Ghimire, J. Rogan and J. Miller, “Contextural LandCover Classification: Incorporating Spatial Dependence in Land-Cover Classification Models Using Random Forests and the Getis Statistic,” Remote Sensing Letters, Vol. 1, No. 1, 2010, pp. 45-54. doi:10.1080/01431160903252327

[11] M. Pesaresi, “Texture Analysis for Urban Pattern Recognition Using Fine Resolution Panchromaticsatellite Imagery,” Geographical and Environmental Modelling, Vol.
4, No. 1, 2000, pp. 43-63. doi:10.1080/136159300111360

[12] F. Dell’Acqua and P. Gamba, "Discriminating Urban Environments Using Multiscale Texture and Multiple SAR Images," International Journal of Remote Sensing, Vol. 27, No. 18, 2006, pp. 3797-3812. doi:10.1080/01431160600557572

[13] A. Puissant, J. Hirsch and C. Weber, "The Utility of Texture Analysis to Improve Per-Pixel Classifications for High to Very High Spatial Resolution Imagery,” International Journal of Remote Sensing, Vol. 26, No. 4, 2005, pp. 733-745. doi:10.1080/01431160512331316838

[14] J. Rogan and D. M. Chen, “Remote Sensing Technology for Mapping and Monitoring Land-Cover and Land-Use Change,” Progress in Planning, Vol. 61, No. 4, 2004, pp. 301-325. doi:10.1016/S0305-9006(03)00066-7

[15] C. T. Chen, K. S. Chen and J. S. Lee, “The Use of Fully Polarimetric Information for the Fuzzy Neural Classification of SAR Image," Transactions on Geoscience and Remote Sensing, Vol. 41, No. 9, 2003, pp. 352-365.

[16] R. J. Dekker, "Texture Analysis and Classification of ERS SAR Images for Map Updating of Urban Areas in the Netherland," Geoscience and Remote Sensing, Vol. 41, No. 9, 2003, pp. 1950-1958. doi:10.1109/TGRS.2003.814628

[17] T. M. Pellizzeri, P. Gamba, P. Lombardo and F. D. Acqua, "Multitemporal/Multi-Band SAR Classification of Urban Areas Using Spatial Analysis: Statistical versus Neural Kernel-Based Approach,” Geoscience and Remote Sensing, Vol. 41, No. 10, 2003, pp. 2338-2353. doi:10.1109/TGRS.2003.818762

[18] Z. Zhu, C. E. Woodcock, J. Rogan and J. Kellndorfer, "Assessment of Spectral, Polarimetric, Temporal, and Spatial Dimensions for Urban and Peri-Urban Land Cover Classification Using Landsat and SAR Data," Remote Sensing of Environment, Vol. 117, 2011, pp. 72-82. doi:10.1016/j.rse.2011.07.020

[19] D. Amarsaikhan and T. Douglas, "Data Fusion and Multisource Image Classification," International Journal of Remote Sensing, Vol. 25, No. 14, 2004, pp. 3529-3539. doi:10.1080/0143116031000115111

[20] C. Corbane, J. Faure, N. Baghdadi, N. Villeneuve and M. Petit, "Rapid Urban Mapping Using SAR/Optical Imagery Synergy,” Sensors, Vol. 8, No. 11, 2008, pp. 71257143. doi:10.3390/s8117125

[21] B. Waske and S. van der Linden, "Classifying Multilevel Imagery from SAR and Optical Sensors by Decision Fusion," IEEE Transaction on Geoscience and Remote Sensing, Vol. 46, No. 5, 2008, pp. 1457-1466. doi:10.1109/TGRS.2008.916089

[22] M. J. Barnsley and S. L. Barr, “A Graph Based Structural Pattern Recognition System to Infer Urban Land-Use from Fine Spatial Resolution Land-Cover Data," Computer, Environment and Urban Systems, Vol. 21, No. 3-4, 1997, pp. 209-225. doi:10.1016/S0198-9715(97)10001-1

[23] J. Mas, A. Pérez-Vega and K. C. Clarke, “Assessing Simulated Land-Use/Cover Maps Using Similarity and Fragmentation Indices,” Ecological Complexity, Vol. 11, 2012, pp. 38-45. doi:10.1016/j.ecocom.2012.01.004 
[24] Republic of Kenya, “Kenya Population Census 1969,” Nairobi, 1970.

[25] Republic of Kenya, "Kenya Population Census 1979," Nairobi, 1981.

[26] Republic of Kenya, "Kenya Population Census 1989,” Nairobi, 1994.

[27] Republic of Kenya, “Economic Survey 2000,” Nairobi, 2000.

[28] W. Mwangi, “Kenya Safaris-Nakuru Travel,” University of Amsterdam, Amsterdam, 2007.

[29] C. O. Obura, "Towards an Environmental Planning Approach in Urban Industrial Sitting and Operations in Kenya: The Case of Eldoret Town,” Netherlands Geographical Studies, Utrecht, 1996.

[30] M. Herold, D. A. Roberts, M. E. Gardner and P. E. Dennison, "Spectrometry for Urban Area Remote Sensing Development and Analysis of a Spectral Library from 350 to 2400 nm," Remote Sensing of Environment, Vol. 91, No. 3-4, 2004, pp. 304-319. doi:10.1016/j.rse.2004.02.013

[31] C. Small, “A global Analysis of Urban Reflectance,” International Journal of Remote Sensing, Vol. 26, No. 4, 2005, pp. 661-681. doi:10.1080/01431160310001654950

[32] P. Griffiths, P. Hostert, O. Gruebner and S. Linden, "Mapping Megacity Growth with Multi-Sensor Data,” Remote Sensing of Environment, Vol. 114, No. 2, 2010, pp. 426439. doi:10.1016/j.rse.2009.09.012

[33] S. Phinn, M. Stanford, P. Scarth, A. T. Murray and P. T. Shyy, "Monitoring the Composition of Urban Environments Based on the Vegetation-Impervious Surface-Soil (VIS) Model by Subpixel Analysis Techniques,” International Journal of Remote Sensing, Vol. 23, No. 22, 2002, pp. 4131-4153. doi:10.1080/01431160110114998

[34] F. Pacifici, F. Del Frate, W. J. Emery, P. Gamba and J. Chanussot, "Urban Mapping Using Coarsesar and Optical Data," IEEE Geoscience and Remote Sensing Letters, Vol. 5, No. 3, 2008, pp. 331-335. doi:10.1109/LGRS.2008.915939

[35] L. Gomez-Chova, et al., "Urban Monitoring Using MultiTemporal SAR and Multi-Spectral Data,” Pattern Recognition Letters, Vol. 27, No. 4, 2006, pp. 234-243. doi:10.1016/j.patrec.2005.08.004

[36] NASA, “Landsat Data Continuing Mission,” 2008. http://ldcm.nasa.gov/index.html

[37] M. A. Wulder, et al., "Landsat Continuity: Issues and Opportunities for Land Cover Monitoring,” Remote Sensing of Environment, Vol. 112, No. 3, 2008, pp. 955-969. doi:10.1016/j.rse.2007.07.004

[38] F. Garestier, P. Dubois-Fernandez, X. Dupuis, P. Paillou and I. Hajnsek, "PolInSAR Analysis of X-Band Data over Vegetated and Urban Areas," IEEE Transactions on Geoscience and Remote Sensing, Vol. 44, No. 2, 2006, pp. 356-364. doi:10.1109/TGRS.2005.862525
[39] F. M. Henderson and A. J. Lewis, "Principles and Applications of Imaging Radar,” 3rd Edition, John Wiley \& Sons, New York, 1998.

[40] Y. Dong, B. Forster and C. Ticehurst, "Radar Backscatter Analysis for Urban Environments,” International Journal of Remote Sensing, Vol. 18, No. 6, 1997, pp. 1351-1364. doi:10.1080/014311697218467

[41] R. Z. Schneider, K. P. Papathanassiou, I. Hajnsek and A. Moreira, "Polarimetric and Interferometric Characterization of Coherent Scatterers in Urban Areas," IEEE Transactions on Geoscience and Remote Sensing, Vol. 44, No. 4, 2006, pp. 971-983. doi:10.1109/TGRS.2005.860950

[42] J. F. Anderson, E. E. Hardy, J. T. Roach and R. E. Witmer, "A Land-Use and Land Cover Classification System for Use with Remote Sensor Data,” U.S. Geological Survey, Washington, 1976.

[43] N. Lam and D. A. Quattrochi, "On the Issues of Scale, Resolution, and Fractal Analysis in the Mapping Sciences," Professional Geographer, Vol. 44, 1992, pp. 88-98. doi:10.1111/j.0033-0124.1992.00088.X

[44] D. P. Ming, J. Y. Yang, L. X. Li and Z. Q. Song, "Modified ALV for Selecting the Optimal Spatial Resolutionand Its Scale Effect on Image Classification Accuracy," Mathematical and Computer Modelling, Vol. 54, No. 3-4, 2011, pp. 1061-1068. doi:10.1016/j.mcm.2010.11.036

[45] T. Idol, B. Haack, S. Sawaya, and A. Sheoran, "Land Cover/Use Mapping with Quad Polarization Radar and Derived Texture Measures,” American Society of Photogrammetry and Remote Sensing, Oregon, 2008.

[46] H. Z. M. Shafri and F. S. H. Ramle, "A Comparison of Support Vector Machine and Decision Tree Classifications Using Satellite Data of Langkawi Island,” Journal of Information Technology, Vol. 8, No. 1, 2009, pp. 64-70. doi:10.3923/itj.2009.64.70

[47] B. Waske and J. A. Benediktsson, "Fusion of Support Vector Machines for Classification of Multisensor Data," IEEE Transaction on Geoscience and Remote Sensing, Vol. 45, No. 12, 2007, pp. 3858-3866. doi:10.1109/TGRS.2007.898446

[48] F. Melgani and L. Bruzzone, "Classification of Hyperspectral Remote Sensing Images with Support Vector Machines," IEEE Transactions on Geoscience and Remote Sensing, Vol. 42, No. 8, 2004, pp. 1778-1790. doi:10.1109/TGRS.2004.831865

[49] C. Huang, L. S. Davis and J. R. G. Townshend, "An Assessment of Support Vector Machines for Land Cover Classification," International Journal of Remote Sensing, Vol. 23, No. 4, 2002, pp. 725-749. doi:10.1080/01431160110040323

[50] R. G. Congalton and K. Green, "Assessing the Accuracy of Remotely Sensed Data: Principles and Practices,” Lewis Publishers, Boca Raton, 1999. 